\title{
Laser treatment for tracheobronchial tumours: local or general anaesthesia?
}

\author{
P J M GEORGE, C P O GARRETT, C NIXON, M R HETZEL, E M NANSON, \\ F J C MILLARD
}

From University College Hospital and St James's Hospital, London

ABSTRACT Ninety seven patients with tracheobronchial tumours have been treated with thष्ठs neodymium yttrium-aluminium-garnet (Nd YAG) laser over a period of 33 months. Fifty one of these patients were treated under local anaesthesia and 46 under general anaesthesia. The results obtained with the two methods have been compared retrospectively. The numbers of patients responding to treatment, the magnitude of the response, and the duration of palliation were similam in the two groups; significantly more treatment sessions, however, were required during each cours $\Phi^{+}$ of treatment under local anaesthesia. This advantage of general anaesthesia was thought to arise्ठ from the ability to continue treatment for longer and with greater efficiency. The use of the rigiक bronchoscope with jet ventilation under general anaesthesia was also thought to provide bette $\overrightarrow{\mathbb{C}_{0}}$ control of the airway and to allow more efficient clearance of blood and mucus. Two operative deaths occurred under local anaesthesia, when bleeding led to asphyxiation, but none have occurred under general anaesthesia. Treatment under general anaesthesia is not, however, without risk and is potentially hazardous in patients with severe chronic hypoxic lung disease.

During the last six years the neodymium yttriumaluminium-garnet (Nd YAG) laser has become established as an important method of palliative treatment in patients with tracheobronchial tumours. $^{1-4}$ The thermal action of the laser is used to resect and cauterise intraluminal tumour within the proximal tracheobronchial tree and breathlessness and haemoptysis can be relieved in selected patients.

Treatment may be given under either local or general anaesthesia. Although each method has gained favour among different groups, no attempt has been made to compare them. We describe our experience with both methods in two hospitals.

\section{Methods}

DESIGN OF THE STUDY

The results of treating patients under local and general anaesthesia have been compared in a retrospective study. Our initial experience with the Nd YAG laser was obtained with local anaesthesia. It is therefore possible that our early data on local

Address for reprint requests: Dr P J M George, University College Hospital, London WCIE 6AU.

Accepted 7 March 1987 anaesthesia might be prejudiced by lack of experience with a new favour of general anaesthesia, the data on locat anaesthesia obtained during our first 18 months work with the laser have been discarded and more recently acquired data relating to local anaesthesi have been compared with our earliest data on genera anaesthesia.

\section{PATIENTS}

During the period of the study, 51 patients $(33$ me and 18 women) were treated under local anaesthesi® (January 1983 to September 1985) and 46 (29 men and 17 women) were treated under generas. anaesthesia (August 1983 to September 1985). Thi histological type of all the tumours is shown i table 1. All patients were suffering from haemoptysiñ or breathlessness and all had intraluminal tumoufu accessible to the fibreoptic bronchoscope.

Pretreatment comparisons indicated that the two groups were well matched. The mean age was 65 year in each group. Mean (SD) values for peak expiratores? flow (PEF) were $201(118) 1 \mathrm{~min}^{-1}$ in the locat anaesthesia group and $185(107) 1 \min ^{-1}$ in the general anaesthesia group, while for the Karnofsk\$ performance index ${ }^{5}$ they were 66 (18) and 64 (23i respectively. Thirty nine $(76 \%)$ patients who were 
Table 1 Histological types of tumours treated by laser under local anaesthesia ( $L A$ ) and general anaesthesia (GA)

\begin{tabular}{lrr}
\hline Cell type & $L A$ & $G A$ \\
\hline Squamous cell & 41 & 26 \\
Adenocarcinoma & 2 & 3 \\
Large cell & 0 & 1 \\
Small cell & 0 & 2 \\
Adenoid cystic & 3 & 0 \\
Carcinoid & 1 & 2 \\
Malignant mixed & 0 & 1 \\
Locally invasive thyroid carcinoma & 1 & 2 \\
Poorly differentiated & 0 & 3 \\
Metastatic & 3 & 6 \\
Total & 51 & 46 \\
\hline
\end{tabular}

treated under local anaesthesia had received previous treatment with either surgery, radiotherapy, or chemotherapy, compared with $30(65 \%)$ patients treated under general anaesthesia.

\section{TREATMENT UNDER LOCAL ANAESTHESIA}

Patients treated under local anaesthesia received an intramuscular injection of atropine and papaveretum as premedication. Bronchoscopy was performed with an Olympus BF 1 T10 fibreoptic instrument with 4\% and $2 \%$ solutions of lignocaine applied topically to the larynx and tracheobronchial tree. A $600 \mu \mathrm{m}$ glass optical fibre was passed through the biopsy channel $(2.6 \mathrm{~mm}$ in diameter) of the bronchoscope and was used to transmit the laser beam. The Nd YAG laser beam was then aimed at the tumour with the aid of a visible helium neon beam coupled to the laser system (Fiberlase 100, Pilkington Medical Systems). Laser irradiation was given in pulses lasting no longer than 2 seconds at a power of 70 watts. Charred tumour debris was removed with flexible biopsy forceps. Bleeding from the bed of the tumour was controlled by applying topical adrenaline $(1 \mathrm{ml}$ of 1:1000 solution diluted in $20 \mathrm{ml}$ saline), followed by further laser photocoagulation. Additional sedation was obtained with intravenous injection of diazepam (5-20 mg), and coughing was suppressed with small doses $(2.5 \mathrm{mg})$ of intravenous diamorphine as required. Oxygen was administered routinely during treatment and was given via a nasal cannula at a rate of $41 \mathrm{~min}^{-1}$.

\section{TREATMENT UNDER GENERAL ANAESTHESIA}

The same premedication was given as for local anaesthesia. General anaesthesia was induced with etomidate and then maintained with intravenous infusions of etomidate and alfentanil. The patient was paralysed with atracurium, intubated with a Storz 7.5 $\mathrm{mm}$ adult ventilating bronchoscope and jet ventilated with a Sanders injector, $100 \%$ oxygen entraining room air being used. The fibreoptic bronchoscope was then passed inside the rigid bronchoscope and was used to aim the laser beam in the same way as under local anaesthesia. Powers of 50-70 watts were used and the coagulated base of tumour was removed with larger rigid biopsy forceps. Control of bleeding was achieved in the same way as under local anaesthesia, although it was additionally possible to remove blood from the airway with a large diameter suction catheter. At the end of treatment the rigid bronchoscope was removed and an endotracheal tube passed. Anaesthesia was maintained with nitrous oxide and oxygen until spontaneous breathing had been restored by the reversal of neuromuscular blockade.

\section{ASSESSMENT OF THE RESPONSE TO TREATMENT}

The response to treatment was not assessed until we were satisfied that we had resected and cauterised as much tumour as possible; in some cases this required up to five treatments during the initial hospital admission. In patients with partially obstructed airways an objective response was taken as an increase of at least $20 \%$ in PEF. In patients with tumours causing complete endobronchial obstruction radiographic evidence of re-expansion of a lung or lobe was required before a response was claimed. In patients with haemoptysis complete remission lasting for at least one month was regarded as an objective response.

\section{STATISTICAL COMPARISONS}

The numbers of patients responding to treatment under local anaesthesia and under general anaesthesia were compared by means of the $\chi^{2}$ test with Yates's correction. All other comparisons were made with Student's $t$ test.

\section{Results}

\section{RESPONSE TO TREATMENT}

Twenty seven patients (53\%) showed an objective response when treatment was given under local anaesthesia, compared with $31(67 \%)$ treated under general anaesthesia (table 2). The proportion of patients responding to treatment under general anaesthesia was greater for each of the three categories of problem treated but these differences were not significant.

In patients successfully treated for partial obstruction the magnitude of the response to treatment was assessed from the change in PEF, this being the most consistently documented measurement of lung function. The mean (SD) increases in PEF for the local and general anaesthesia groups were respectively $86 \%$ $(92 \%)$ and $114 \%(115 \%)$. The PEF responses were further considered according to the site of the tumour within the tracheobronchial tree; they were greatest in 
Table 2 Indications for laser treatment and response of patients treated under local anaesthesia (LA) and general anaesthesia $(G A)$

\begin{tabular}{lcc}
\hline Group & No & $\begin{array}{r}\text { No (\%) showing } \\
\text { objective response }\end{array}$ \\
\hline $\begin{array}{l}\text { LA } \\
\text { Partial obstruction }\end{array}$ & 34 & $19(56)$ \\
$\begin{array}{l}\text { Complete obstruction } \\
\text { Haemoptysis }\end{array}$ & 4 & $1(25)$ \\
Total & 13 & $7(54)$ \\
\cline { 2 - 3 } GA & 51 & $27(53)$ \\
Partial obstruction & & \\
Complete obstruction & 30 & $22(73)$ \\
Haemoptysis & 6 & $2(33)$ \\
Total & 10 & $7(70)$ \\
\hline
\end{tabular}

patients with proximally situated tumours and tended to be greater when treatment was given under general anaesthesia. None of these differences, however, attained statistical significance.

\section{NUMBERS OF TREATMENT SESSIONS GIVEN IN EACH COURSE}

Responders Patients who showed objective responses received additional courses of treatment when their symptoms returned; 27 patients responding to treatment under local anaesthesia received 35 courses of treatment on separate hospital admissions, while the 31 patients responding to treatment under general anaesthesia received 57 courses. Under local anaesthesia, an average of 1.97 treatment sessions was required in each course to obtain a response, compared with only one treatment session under general anaesthesia (figure). This difference was highly significant $(\mathrm{p}<0.001)$.

Non-responders The 24 patients who did not respond to treatment under local anaesthesia received an average of 1.75 treatment sessions (figure). In each case treatment was continued until all treatable tumour had been resected and cauterised. With general anaesthesia, treatment could be completed in one session in all but one patient of the 15 non-responders. The overall difference between the two groups was significant at the $5 \%$ level.

INTERVALS BETWEEN COURSES OF TREATMENT Eight patients having local anaesthesia and 13 patients having general anaesthesia received additional courses of treatment. These patients were retreated when their symptoms returned, and so the intervals between courses provide a rough guide to the duration of their palliation. The mean (SD) duration was 147 (164) days and 79 (54) days for the local and general anaesthesia groups respectively. The difference between the two groups was not, however, significant.
Mean

No of

treatments

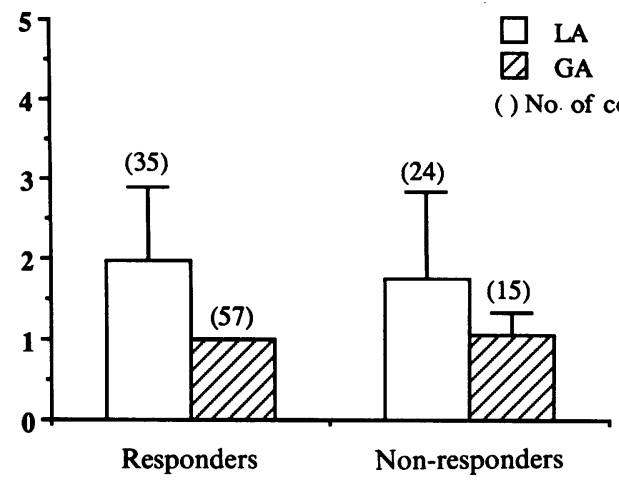

Mean number of treatment sessions (with standard deviations) given during each course of treatment, under local anaesthesia ( $L A)$ and under general anaesthesia $(G A)$, to responders and non-responders. Patients who responded underwent subsequent courses of treatment when their symptoms returned.

\section{DURATION OF HOSPITAL ADMISSION}

The average time spent in hospital during each course of treatment was calculated for the local and generail anaesthesia groups. This information was not dockmented in the records of five patients, while data from five admissions in which patients died in hospital wepae not included as the periods in hospital were spuriousfy short. The mean (SD) length of stay in hospital 严 patients treated under local anaesthesia was 9.9 (7. days, compared with 7.8 (4.4) days in patients treated under general anaesthesia. This difference did ngt quite attain statistical significance $(0 \cdot 1>p>0 \cdot 05)$.

\section{PERIOPERATIVE COMPLICATIONS}

Table 3 summarises the main complications see्en

Table 3 Complications associated with laser treatment under local anaesthesia and general anaesthesia

\begin{tabular}{|c|c|c|}
\hline & $L A^{*}$ & \\
\hline $\begin{array}{l}\text { Haemorrhage leading to operative death } \\
\text { Myocardial infarction } \\
\text { Pneumonia } \\
\text { Tracheo-oesophageal fistula } \\
\text { Dysrhythmia } \\
\text { Cerebrovascular accident } \\
\text { Respiratory failure requiring mechanical ventilation }\end{array}$ & $\begin{array}{l}2(2) \\
3(1) \\
1(1) \\
- \\
= \\
-\end{array}$ & $1 \frac{1}{\mathbb{D}}$ \\
\hline Total & 6 & \\
\hline $\begin{array}{l}\text { Total number of patients treated } \\
\text { Total number of treatments }\end{array}$ & $\begin{array}{r}51 \\
111 \\
\end{array}$ & \\
\hline \multicolumn{3}{|c|}{$\begin{array}{l}\text { "Number of patients dying as a result of the complication showi } \\
\text { in parentheses. }\end{array}$} \\
\hline
\end{tabular}


within the first 12 hours of treatment. There were 13 serious complications, representing $7 \%$ of all treatment sessions.

A total of four treatment related deaths occurred in the local anaesthesia group as compared with one in the general anaesthesia group. The two operative deaths (one at each hospital) both occurred during treatment under local anaesthesia; details from one of these patients have already been published. ${ }^{4}$ In both cases death was caused by asphyxia when bleeding further compromised an already narrowed major airway. No operative deaths have occurred under general anaesthesia; one patient, however, developed a tracheo-oesophageal fistula immediately after treatment under general anaesthesia and then died 11 days later.

Cardiovascular complications occurred with similar frequencies in the two groups but only accounted for one post-operative death, after treatment under local anaesthesia; this patient suffered a myocardial infarction at the time of his treatment and died two days later. One patient with severe chronic bronchitis and emphysema required mechanical ventilation for 12 hours owing to temporarily inadequate respiratory drive after treatment under general anaesthesia. A trivial but painful complication of treatment under general anaesthesia has been brief periods of thrombophlebitis associated with etomidate infusions. These have been seen in nearly all patients treated.

\section{Discussion}

The important advantage of treatment under general anaesthesia is that it can be performed under the best possible conditions for the operator. Muscle relaxation allows control of ventilation and so provides a stationary target for the laser, while the use of large rigid biopsy forceps allows relatively large quantities of tumour debris to be removed quickly and efficiently. Use of the fibrescope through the rigid bronchoscope gives the same range of access to the bronchial tree as fibreoptic bronchoscopy alone. Treatments are usually completed within two hours, but can be extended up to three hours. For physicians, the important practical disadvantages relate to the logistical problems of providing general anaesthesia in an endoscopy suite.

Treatment under local anaesthesia has the advantage of being simple and easy to set up; it is more time consuming however, and less efficient than treatment under general anaesthesia. Tumour debris is removed more slowly with smaller flexible biopsy forceps. The use of higher powers of 70 watts ensures that a greater proportion of the tumour is vaporised and that less needs to be removed with forceps. Treatments cannot, however, usually be tolerated by the patient for longer than one hour, owing to the discomfort caused by the bronchoscope and the irritant effect of smoke generated by tumour vaporisation, and maximum clearance of tumour can rarely be achieved in this time. Consequently, several treatments are required to obtain a response. It is obviously desirable to clear the airway as well as possible at the first treatment since postoperative exudation from tumours occurs and can reduce the airway lumen considerably. ${ }^{6}$

Although the present study was conducted retrospectively, we believe that the results support the practical advantages of treatment under general anaesthesia. An average of 1.97 treatments was required under local anaesthesia to obtain a response, compared with only one under general anaesthesia. Similarly, in the case of patients who did not respond, significantly more treatments were required under local than under general anaesthesia before the decision to abandon further treatments could be made. The use of general anaesthesia therefore resulted in a considerable saving in time for operator and endoscopy 'staff, and furthermore patients tended to spend less time in hospital. The number of patients responding to treatment, the magnitude of the response, and the duration of palliation did not differ significantly between the two groups. It would therefore appear that, although more treatments were required with local anaesthesia, the final results were similar to those obtained under general anaesthesia.

Thirteen serious complications were observed during this study, representing $7 \%$ of all treatment sessions. Although these were equally distributed between the two groups, we suspect that each method is prone to its own particular problems. Bleeding from tumours is often provoked during treatment sessions and may compound the respiratory distress in patients with already narrowed airways. Although it occurred with similar frequency and severity in the two groups, it was undoubtedly easier to control under general anaesthesia. The use of the rigid bronchoscope with jet ventilation provided better airway control and allowed more rapid and efficient clearance of blood and mucus with the aid of a larger diameter suction catheter. Thus, while there were two operative deaths under local anaesthesia, none occurred under general anaesthesia. This experience is consistent with that of Dumon and colleagues, ${ }^{7}$ who reported no operative deaths in over 1500 treatments performed almost exclusively under general anaesthesia.

Many of the patients treated under both local and general anaesthesia had severe chronic hypoxic lung disease. Although laser treatment may improve lung function by relieving obstruction within the large airways, ventilation under general anaesthesia is potentially hazardous in these patients. Of the 46 patients 
treated under general anaesthesia, only one required ventilation as a result of temporarily inadequate respiratory drive; since completing this study, however, we have been obliged to ventilate three other patients for up to seven days.

Ideally, techniques of treatment under local and general anaesthesia should be compared in a strictly controlled prospective study. We have been so impressed, however, by the improvement since developing the technique with general anaesthesia that such a study would be difficult to justify, we believe, on ethical grounds. Clearly, there are patients with severe coexistent cardiorespiratory disease in whom limited and localised tumour might be effectively removed in one session in greater safety under local anaesthesia, but in our experience such cases are rare.

We would therefore recommend that clinicians wishing to develop facilities for laser treatment should employ techniques which use general anaesthesia and rigid bronchoscopy. Moreover, we believe that the combined use of flexible and rigid bronchoscopes exploits the advantages of both instruments.

This work was generously supported by Pilkington Medical Systems and the Department of Health and Social Security. We are also indebted to Dr T N Mills,

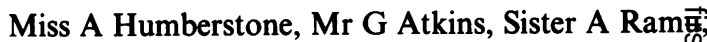
and the endoscopy suite nursing staff for their invaluable assistance.

\section{References}

1 Toty L, Personne C, Colchen A, Vourc'h \& Bronchoscopic management of tracheal lesions usieg the neodymium-yttrium-aluminium-garnet laser Thorax 1981;36:175-8.

2 Dumon JF, Reboud E, Garbe L, Aucomte F, Meric Treatment of tracheo-bronchial lesions by laser phot resection. Chest 1982;81:278-84.

3 McDougall JC, Cortese DA. Neodymium-YAG laset therapy of malignant airway obstruction. A preliminary report. Mayo Clin Proc 1983;58:35-9.

4 Hetzel MR, Nixon C, Edmonstone WM, et al. Laser treatment in 100 tracheobronchial tumours. Thor $\overline{x x}$ 1985;40:341-5.

5 Karnofsky DA, Burchenal JH. The clinical evaluation 9 f chemotherapeutic agents in cancer. In: MacLeod C eg. Evaluation of chemotherapeutic agents. New Yors Columbia University Press, 1948.

6 Dierkesmann R, Huzly A. Side effects of endobronchral laser treatment. Endoscopy 1985;17:49-53.

7 Dumon JF, Shapshay S, Bourcerau J, et al. Principles safety in application of neodymium-YAG laser ii bronchology. Chest 1984;86:163-8. 